\title{
Volume conversion
}

\begin{tabular}{llll}
\hline Unit & Abbreviation & \multicolumn{2}{c}{ In cubic meters $\left(\mathrm{m}^{3}\right)$} \\
\hline 1 femtoliter & $\mathrm{fL}$ & 0.000000000000000001 & $1 \times 10^{-18}$ \\
1 picoliter & $\mathrm{pL}$ & 0.000000000000001 & $1 \times 10^{-15}$ \\
1 nanoliter & $\mathrm{nL}$ & 0.000000000001 & $1 \times 10^{-12}$ \\
1 microliter & $\mu \mathrm{L}$ & 0.000000001 & $1 \times 10^{-9}$ \\
1 milliliter & $\mathrm{mL}$ & 0.000001 & $1 \times 10^{-6}$ \\
1 liter & $\mathrm{L}$ & 0.001 & $1 \times 10^{-3}$ \\
1 cubic meter & $\mathrm{m}^{3}$ & 1 & $1 \times 10^{0}$ \\
\hline
\end{tabular}


